\title{
Cenas etnográficas para entender representações de masculinidades na escola
}

Ethnographic scenes to understand masculinities representations in school

Luciana Borre Nunes*

Universidade Federal de Pernambuco

Resumo Neste texto, busca-se entender o processo de constituição de masculinidades a partir das interações entre um grupo de vinte crianças e as imagens presentes em seu cotidiano escolar. Apresentam-se os resultados da investigação de doutorado concluído em 2014, pelo Programa de Pós Graduação em Arte e Cultura Visual da Universidade Federal de Goiás (Brasil). A perspectiva teórica está centrada nas discussões pós-estruturalistas dos estudos da cultura visual, educação, gênero e sexualidades. A metodologia de investigação percorreu um viés etnográfico com utilização de grupos focais, fotografias e diário de campo como instrumentos de produção de dados. O texto está organizado em duas partes: (1) cultura visual e possibilidades etnográficas em pesquisas com crianças e; (2) representações de masculinidades em sala de aula a partir dos estudos de gênero e sexualidades.

PALAVRAS-ChAVE: Cultura visual; Escola; Masculinidades; Etnografia.

Abstract This paper sets out to reach an understanding of the process of how masculinities ae formed based on interactions between a group of twenty children. The results of a doctoral research paper are presented, which was submitted in 2014, as part of the Post-Graduate Program in Art and Visual Culture of the Federal University of Goiás (Brazil) The theoretical perspective focuses on post-structuralist discussions of studies on visual culture, education, gender and sexualities. The research methodology took an ethnographical slant and used focus groups, photographs and a field diary as instruments for producing data. The text is organized into two parts: (1) visual culture and ethnographic possibilities in research studies on children and; (2) representations of masculinities in the classroom based on gender and sexuality studies.

KEYWORDS: Visual culture; School; Masculinities; Ethnography. 


\section{Introdução}

Percebemos que a rede de produção, criação e expansão das imagens passa por um crescente processo de interesse e reconhecimento nas investigações em ciências humanas e sociais. Como professores, entendemos que no campo da educação, este interesse se deve a uma invasão de imagens que ronda o cotidiano das salas de aula, sendo promovida, principalmente, pelas tecnologias de informação e comunicação. Tornou-se necessário pensar reflexivamente os processos educativos e sua relação com uma gama de imagens/artefatos culturais que produzem maneiras de pensar, agir, sentir e falar.

Reverenciadas, almejadas, negociadas, repudiadas e/ou ignoradas as imagens estão inseridas em jogos de poder e sistemas narrativos de legitimação que contribuem para a construção de subjetividades. Sua amplitude nos provoca a pensar que "aprendemos mais com elas do que somos capazes de conscientemente reconhecer, interpretar e criticar" (TOURINHO; MARTINS, 2013, p. 14).

Imagens dizem o tempo todo sobre nós, denunciando crenças, evidenciando valores e construindo convicções. Cada artefato cultural mostra e constrói traços de nossa cultura e marcas daquilo que vivenciamos e compartilhamos no dia a dia em uma trama rizomática de produção e reprodução. Como determinadas imagens são produzidas? Em qual contexto? Quem exerce protagonismo na construção de artefatos culturais e por quê? Quem detém legitimidade no jogo das políticas de representação? Quem narra e quem tem sua história contada e/ou legitimada?

A perspectiva dos estudos da cultura visual que desenvolvemos durante a investigação de doutorado está preocupada com diferentes olhares sobre a relação/mediação com imagens. O diálogo com os estudos de gênero e sexualidades possibilitou compreender um pouco mais a constituição de masculinidades em âmbito formal de ensino.

Os caminhos metodológicos etnográficos foram traçados ao longo da investigação com um grupo de vinte crianças (entre 8 e 11 anos de idade) de uma escola da rede pública de ensino em Goiânia/Brasil.

As discussões deste artigo estão alicerçadas na perspectiva pós-estruturalista em cultura visual, gênero e sexualidades e apresentam os resultados da investigação de doutorado: "Se a prova fosse sobre os rebeldes eu ia tirar 10!" culturas visuais tramando masculinidades na escola, concluído em 2014, pelo Programa de Pós Graduação em Arte e Cultura Visual da Universidade Federal de Goiás (Brasil).

O texto está organizado em duas partes: (1) cultura visual e possibilidades etnográficas em pesquisas com crianças e; (2) representações de masculinidades em sala de aula a partir dos estudos de gênero e sexualidades.

\section{Cultura visual e possibilidades etnográficas}

As proposições da cultura visual com as quais compartilhamos estão imbuídas por um interesse pelas mediações/relações que detemos com imagens/artefatos 
culturais, problematizando a construção de visualidades através de relações de poder e políticas de representação que engendram interpretações e dizem, em parte, como somos. Durante a pesquisa não realizamos análise ou leitura das imagens que circundavam o ambiente escolar, mas, procuramos pistas sobre como aconteciam as relações entre crianças e tais artefatos e como isso também afetava nossos posicionamentos e "versões de realidade" enquanto professores.

Orientados por um viés etnográfico, os dados da pesquisa foram produzidos e analisados baseados no suporte teórico e contribuições dos estudos da cultura visual e dos estudos de gênero e sexualidades numa perspectiva pós-estruturalista. As estratégias para produção de dados foram: elaboração de grupos focais; anotações em diário de campo e o desenvolvimento de uma ação pedagógica com fotografias.

O estranhamento, decorrente de uma abordagem etnográfica pós-estruturalista, põe em perspectiva a importância de duvidar e suspeitar daquilo que parece estabelecido e estável no âmbito escolar. Contribui para desestabilizar 'verdades' consolidadas como naturais ao mesmo tempo em que ajuda a resistir à tentação de formular sínteses conclusivas. Busca, também, familiarizar-nos com o estranho ajudando a “... admitir a provisoriedade do saber e a coexistência de diversas verdades que operam e se articulam em campos de poder-saber; de aceitar que as verdades com as quais operamos são construídas, social e culturalmente" (MEYER; SOARES, 2005. p. 39).

Pesquisas com esta abordagem tomam como referência deslocamentos e movimentos em vez de ambicionar pontos de chegada. Procuram refletir sobre os processos nos quais verdades são consolidadas, neste caso, como masculinidades são produzidas nas salas de aula através de imagens.

O paradigma qualitativo, com uma abordagem do tipo etnográfico, se adaptou aos anseios da investigação, pois, produzimos dados sobre a constituição de identidades masculinas em momentos de aulas, através de um período prolongado de observação e envolvimento sistemático com o grupo pesquisado. André (1991, p. 38) ao apresentar considerações sobre este viés de pesquisa, destaca questões relacionadas ao processo de interação entre pesquisador e participantes:

$\mathrm{O}$ que caracteriza mais fundamentalmente a pesquisa do tipo etnográfico é, principalmente, um contato direto e prolongado do pesquisador com a situação e as pessoas ou grupos selecionados. Evidentemente deve ficar claro, desde o início da pesquisa, o grau de envolvimento ou de participação do pesquisador na situação pesquisada. A intensidade do envolvimento pode variar ao longo do processo de coleta dependendo das exigências e especificidade do próprio trabalho de campo. O que parece fundamental é que o pesquisador tenha muito claro em cada momento por que certo grau de participação e não outro está sendo assumido e saiba avaliar prós e contras desta ou daquela opção. (ANDRÉ, 1991, p. 38).

Complementando a descrição sobre o envolvimento do pesquisador e as especificidades da pesquisa etnográfica, a autora explica que é necessário um grande número de dados descritivos para a realização de uma pesquisa etnográfica. Esses dados 
são oriundos, principalmente, das observações, nas quais "o pesquisador vai acumulando descrições de locais, pessoas, ações, interações, fatos, formas de linguagem e outras expressões, que lhe permitem ir estruturando o quadro configurativo da realidade estudada, em função do qual ela faz suas análises e interpretações” (ANDRÉ, 1991, p. 38).

Identidades são construídas em diversos âmbitos a partir de relações e inter -relações que se processam mutuamente. A escola apresenta notável reconhecimento social como local de importante formação intelectual e relacional, mesmo que assolada por diversas dificuldades e mecanismos de desvalorização. É local de intensas convivências e relacionamentos que modificam as atribuições que as instituições escolares detêm. Procuramos entender as questões referentes às escolas com um olhar mais amplo da sociedade, sendo que nossa opção pela escola como foco de estudo não implicou abordá-la em suas relações internas. "Trata-se, ao contrário, de considerá-la como parte de uma totalidade social que de alguma maneira a determina e com a qual ela mantém determinadas formas de relacionamento" (ANDRÉ, 1991, p. 44).

A imersão na escola por prolongado período proporcionou o registro de ações que, talvez, não fossem vistas ou percebidas em um curto período de observação. Acontecimentos marcantes para o desenvolvimento do estudo aconteceram de maneira rápida durante as aulas e alertaram para a necessidade de estarmos atentos a sutileza de certas práticas educativas e compreender que "o observar na pesquisa de campo implica na interação com o outro evocando uma habilidade para participar das tramas da vida cotidiana, estando com o outro no fluxo dos acontecimentos" (ECKERT; ROCHA, 2008, p. 4).

As contribuições da antropologia, no que diz respeito a prática da pesquisa etnográfica na área da cultura visual, são evidentes. Essas contribuições estão associadas a uma perspectiva contemporânea ao conceber a pesquisa etnográfica como espaço de troca de experiências e intercomunicabilidade.

A participação na rotina escolar e a interação com estudantes, professoras e equipe diretiva, proporcionou diálogos entrecruzando nossos olhares com os olhares e percepções das/os colaboradores da investigação. A pesquisa etnográfica orientada para o exercício de olhar e de escuta "impõe ao pesquisador ou a pesquisadora um deslocamento de sua própria cultura para se situar no interior do fenômeno por ele ou por ela observado através da sua participação efetiva nas formas de sociabilidade por meio das quais a realidade investigada se apresenta" (ECKERT; ROCHA, 2008, p. 2).

Procuramos estar atentos aos pequenos acontecimentos, embora tenhamos consciência que muitos devem ter passado sem que percebêssemos. A prática etnográfica pressupõe algumas especificidades. Entre elas, o fato de que análises configuram-se como verdades provisórias nas quais considerações são construídas através de jogos de poder. $\mathrm{O}$ caráter dialógico enfatiza a busca por diferentes vozes que negociam suas verdades e que apontam para reflexões diferenciadas. Isso se constitui como uma ferramenta não somente produtiva como desejada para possíveis interpretações das/ os pesquisadoras/es. Sobre esta dimensão dialógica e sobre outras especificidades da pesquisa etnográfica, Clifford (1991, p. 33) diz o seguinte: 
A escrita etnográfica, então, é determinada de seis maneiras: (1) a partir do contexto (descrição de significados sociais); (2) pela retórica (uso e desuso de convencionalidades expressivas); (3) pela desinstitucionalização (contra tradições específicas, disciplinas que enrijecem o receptor da mensagem); (4) pela generalização (pois, em geral, é fácil descobrir um etnógrafo entre um romancista ou entre alguns simples viajantes); (5) pela politização (toda autoridade e todo autoritarismo cultural que buscam uni dimensão do discurso devem ser contestados); (6) pelo historicismo (é necessário conhecer a história para alcançar a origem dos lugares comuns). Este é o que dá coerência às ficções etnográficas, este é o que determina, este é o princípio de que as orienta (CLIFFORD, 1991, p. 33).

A prática etnográfica exigiu observação atenta, disposição para escutar e a condição de imersão no grupo. Além disso, nenhuma das considerações pode ser vista como uma análise correta ou verdadeira porque "na etnografia não há verdades absolutas, mas parciais, incompletas" (CLIFFORD, 1991, p. 34). Logo, todas as considerações partem de nossas vivências e podem apresentar outros olhares se oriundas de outras práticas investigativas e experiências pessoais.

Investigar e pensar imagens pressupõe um olhar atento a uma parte das inúmeras e diferentes ligações entre o artefato visual, seu contexto e as subjetividades dos produtores e receptores. Assim, "as imagens, assim como a linguagem, são mediadoras de significados e cada interpretação é um modo de pensar do(s) indivíduo(s), fragmento subjetivo de uma realidade, de um contexto, de uma comunidade" (TOURINHO; MARTINS, 2013, p. 64).

Estudar o visual não pressupõe investigar somente as imagens, mas, entendê -las como produtoras e produto de construções de sentido. Imagens não são simplesmente uma representação pictórica dos fatos cotidianos, pois carregam e constroem vivências. Evidenciam um encontro entre nossa prática social do olhar, subjetividades e negociações sociais, sendo que "esse ponto de encontro permite pesquisar as relações entre os artefatos da cultura visual e aquele que vê (e é visto), e os relatos visuais que, por sua vez, constroem o visualizador" (HERNANDEZ, 2013, p. 83).

Os sentidos que surgem dessa relação são apropriados, negociados, rejeitados e, até mesmo, não percebidos. O fato é que algumas 'versões de realidade' se tornam hegemônicas, verdades legitimadas. A cultura visual estuda "visualidades e artefatos visuais compreendidos através de situações e circunstâncias de constante conflito - pelo poder de ver, de ser visto, de controlar o que pode ser visto e, ainda, de organizar campos de visualidades para diferentes tipos de recepção/interação" (TOURINHO; MARTINS, 2013, p. 64).

As imagens não são detentoras da verdade e não constituem certa amostragem da realidade. As interpretações que damos as imagens são incompletas, parciais e até fictícias, dependendo de cada olhar imbuído por ideias, crenças, vontades e desejos. Cada imagem faz sentido em um contexto específico e não atende somente aos objetivos de seu produtor, mas, aos sentidos que despertará, ou não, naqueles que a apreende e em seus modos de representação. 
A investigação com viés etnográfico com crianças foi uma oportunidade para ouvir e buscar entender suas histórias, ansiedades e conflitos ajudando-nos a refletir sobre as cenas, organizando e criando outras histórias. Foram momentos que propiciaram espaço para narrar o cotidiano dessas crianças registrando falas, gestos e imagens do seu dia a dia, compartilhando seus comentários, provocando estranhamentos sobre nossas conversas e gerando reflexões a partir dos materiais visuais que traziam.

\section{Tramas de gênero e sexualidades na escola}

Meninos aprendem, dentro e fora da escola, um código social que valoriza padrões de masculinidade desejáveis e muitas vezes associados à virilidade, heterossexualidade e repúdio a características ditas femininas.

Estudar essas relações com o visual nos levou a entender, mesmo que provisoriamente, aspectos culturais dos quais nós e as crianças fazemos parte. A naturalização de determinadas narrativas são práticas políticas. Práticas inseridas em relações de poder que estão em constante negociação. Por exemplo, o desenho animado Ben 10 assim como outros discursos, legitima a heterossexualidade afirmando e mostrando que isso é 'o' natural. Ao ser naturalizado, aquilo que não se enquadra no parâmetro da normalidade, passou a ser repudiado pelas crianças. Os meninos mantinham suas masculinidades em constante negociação e, na teia das relações de poder, demonstravam preconceitos contra aqueles que não atendiam a normativa sexual, mantendo seu lugar no grupo.

Interessa-nos pensar sobre os processos sociais pelos quais os meninos transitam, os modos como eles negociam seus lugares diante do grupo de convivência na escola e como eles assumem ou descartam formas de masculinidades. Uma das negociações que estava em jogo nas relações entre os meninos participantes da pesquisa era a transição de uma masculinidade infantil para uma masculinidade adolescente. Nesse caso, o infantil deveria ser superado para alcançar atitudes mais "viris", conquista de conhecimentos sobre sexo e imposição de vontades através de atos de agressão e violência.

Steve (8 anos) é um dos meninos que contou sobre sua admiração pelo personagem Ben 10. Mostrou a fotografia de seu cobertor estampado com o personagem e falou sobre seu boneco gigante para os colegas durante encontro do grupo focal. Steve foi interrompido por seu colega Leonardo (11 anos) que disse: "é hora de largar os super -heróis e virar homem". Heitor corroborou com as palavras do colega afirmando: "eu já deixei o Ben $10 \mathrm{faz}$ tempo... só uso as roupas porque minha mãe compra". Leonardo ainda reiterou: "bonecos são coisa de menina". Steve ficou desconcertado e os meninos ficaram em silêncio aguardando uma resposta. Timidamente, o menino disse que as roupas do 
Imagem 1 - Registros feitos por Steve sobre personagem Ben 10 (2011).
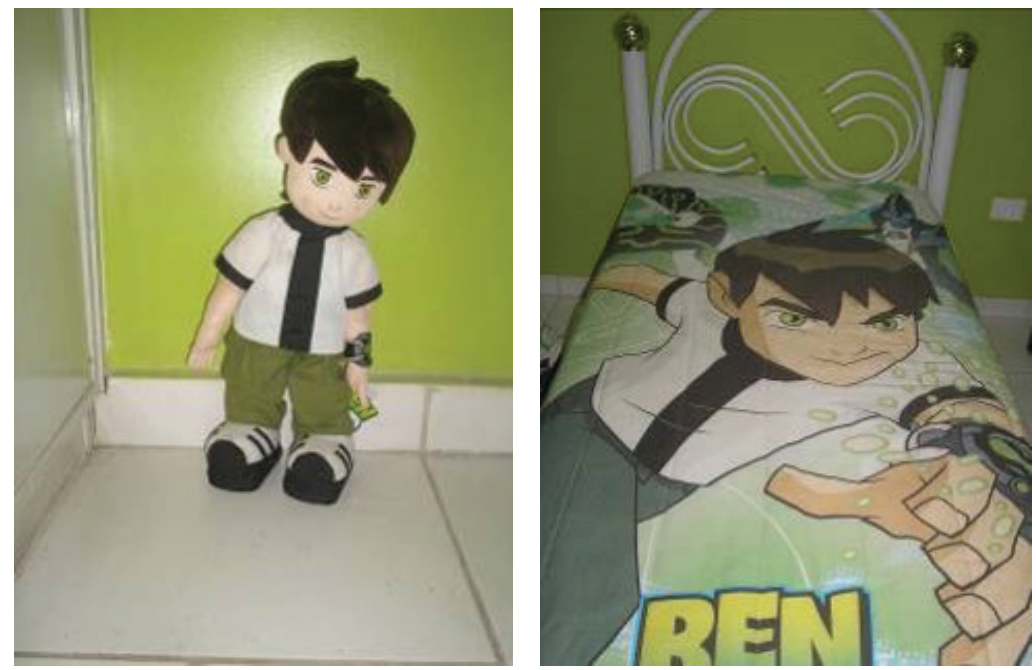

Ben 10 foram compradas por sua avó, tentando se desculpar ou justificar o porquê de ainda ser fã desse personagem.

Nossa inquietação diante desses comentários é que, sendo a escola um lugar de intensas relações interpessoais e aprendizagens culturais que demarcam maneiras de conviver, problematizações sobre como percebemos o mundo deveriam ser oportunizadas pelas/os educadoras/es. Pensamos a escola com inúmeros desafios que transcendem os interesses de transmissão de conteúdos pré-estabelecidos e que provocam a pensar as relações que as crianças tem com as imagens e artefatos visuais do seu cotidiano e as relações com seus grupos de convivência.

Não nos parece relevante pensar se Steve aprendeu a não gostar do Ben10 ou se ainda continuará apreciando o personagem. O importante é refletir sobre como Steve negociou suas representações de masculinidade e encontrou uma maneira de não ser penalizado ou menosprezado pelo grupo. Naquele grupo, espaço e momento, ele aprendeu que um menino de sua faixa etária não deve manifestar seu gosto por "coisas de crianças" e que suas preferências deveriam mudar, amadurecer, para atender a uma masculinidade considerada adulta.

Ao dizer que Steve deveria "virar homem", Leonardo se colocou em uma posição superior, como alguém que já passou por experiências de vida distanciando-se da ingenuidade da fase dos super-heróis. Deixou para trás - assim queria demonstrar seu período de fantasia e imaginação e usou isso para mostrar poder perante os colegas. $\mathrm{Na}$ sua perspectiva, possivelmente, revelou conhecimento e maturidade. Conseguiu impor seus desejos e foi admirado por isso. Seus conhecimentos como menino "mais velho" da turma representaram um valor social, um capital que favoreceu a prevalência de suas perspectivas. No jogo de negociações, Leonardo foi portador de conhecimentos que se constituíram como valiosa moeda de troca. A postura contrária à infância proporcionou um capital cultural prestigiado e valorizado nas interações entre os me- 
ninos. Esse prestígio o encorajou a oprimir e subordinar os demais aos seus interesses e conhecimentos.

Essas negociações geram aprendizagens. Os meninos aprendem como agir em determinados momentos e ambientes. Concordo com Garcia (2012, p. 147) ao afirmar que "é importante continuar refletindo sobre quais normalidades de gênero e sexo são dominantes em determinados contextos e os modos como negociamos com elas, movimentando-nos entre as margens de resistência e conformidade". Em princípio, a instituição escolar - junto com outras instituições socioculturais - detém a atribuição de oportunizar problematizações sobre as maneiras naturalizadas de pensar e agir nos grupos, propor mudanças nos modos e focos de olhar, transgredindo e criando outras relações e formas de conviver que fujam de confortos e estabilidades que nos prendem a poucas possibilidades de interpretar e compreender acontecimentos sociais.

Ao mesmo tempo em que estamos imersos nas relações de gênero, também as produzimos e reproduzimos. Não somos receptores e expectadores inocentes que simplesmente herdam, aderem ou assumem um gênero, mas, também construímos estratégias para continuar repetindo comportamentos específicos para homens e mulheres. Sendo assim, "reconhecer o gênero como um padrão social exige vê-lo como um produto da história e também como um produtor de história” (CONNELL, 2003, p. 46).

Isso não significa que ele passou a não gostar desses brinquedos, mas, naquele grupo, ele aprendeu a criar estratégias de convivência para não ser ridicularizado ou comparado com meninas. É possível que as crianças não acreditassem que o boneco de Steve fosse brinquedo de menina, mas o colega "mais experiente" detinha credibilidade para narrar a situação. Neste mesmo encontro outro colega, Junior, ergueu a foto da camiseta de seu time de futebol preferido e disse: "homem tem é que gostar disso!" Apaixonado por futebol e pelo time do Flamengo, Junior citou as várias medalhas dos campeonatos nos quais participou e utilizou essa "paixão" e o relato de sua rotina de treinos como dispositivo para não deixar dúvidas e consolidar sua masculinidade. $\mathrm{O}$ fato é que, diante do grupo e de determinadas situações e ambientes, elas/es aprendem como interagir e negociar suas atitudes e crenças para se integrarem e participarem de um projeto de convivência. Ao fazerem isso, suas percepções, maneiras de ser, agir e pensar também estão sendo modificados, estando em constante transformação. Askew e Ross (1991, p. 17) afirmam que "grande parte da conduta descrita como masculina é aprendida (oposto a inata) e que se reforça por ideias estereotipadas sobre o que significa ser homem na sociedade".

Mecanismos de disciplinamento na escola reafirmaram comportamentos específicos sobre ser menino e menina, desvalorizando ou marginalizando aquelas/es estudantes que não atendiam os padrões estabelecidos. Comportamentos são controlados e as crianças aprendem a não falar o que pensam e sentem em sala de aula. Para serem aceitos nos grupos, meninos aprendem a combater semelhanças com o universo feminino e entendem que a agressividade é atitude inerente ao masculino.

Há uma multiplicidade de masculinidades permeadas por imagens e ar- 
tefatos culturais na escola. Mesmo assim, as crianças estão inseridas em recorrentes narrativas heteronormativas que produzem uma das principais fontes de aprendizagem sobre gênero e sexualidades. A ausência de histórias, personagens ou situações não heteronormativas no repertório visual das crianças produz a naturalização de uma única maneira de viver as relações sociais. A exclusão e ridicularização de colegas que não atendem a masculinidade hegemônica é uma das reverberações deste processo normatizador.

"Vem brigar se você é homem" é uma das frases que escutamos repetidas vezes neste grupo. Agressividade e atitudes violentas foram artifícios utilizados pelos meninos na defesa da heterossexualidade e, consequentemente, da afirmação de masculinidades. Outro aspecto percebido durante a investigação foi a relação entre ensinamentos religiosos e homofobia, gerando especial impacto em nossa atuação como educadores. Presenciar este tipo de situação produziu desconforto e fomos instigados a pensar, falar, discutir e escrever sobre práticas pedagógicas de combate a discriminações e preconceitos. A conversa sobre "coisas que os meninos devem gostar" continuou:

- Existem regras para ser menino? (Pesquisadora)

- Não namorar com homem, com gay. (Diogo, 10 anos)

- E, também, não usar saia ou calcinha. (Lucas, 8 anos)

- Quando os meninos do $4^{\circ}$ ano estão desconfiando que a gente tá de calcinha eles vem e abaixam a nossa calça. Só pra ver se a gente tá de calcinha. (Artur, 8 anos)

- O menino da outra turma era gay. Ele saiu da escola. (Lucas)

- Tia, o Samuel é gay, mas nem parece porque ele é muito forte. Um dia um menino veio me bater e ele disse pra não bater. (Diogo)

- É viado! O Jesus não fez ele pra ser gay, fez pra ser homem. O Jesus fez. Ele tá confuso. (Lucas)

- Não fez pra namorar com homem. Fez a gente namorar com mulher. Foi Deus! (Diogo)

Pedi para explicarem o significado de "estar confuso":

- O Jesus fez ele homem e não mulher e ele tem que ficar com mulher, mas ele gosta de homem. (Lucas)

- É horrível! Porque ele gosta de homem e não pode. (Flávio, 9 anos)

As práticas religiosas dessa escola da rede pública de ensino, supostamente laica, surpreenderam-nos porque foram demarcadas como ações pedagógicas. O direcionamento religioso era valorizado pelas/os professoras/es e pela comunidade escolar como sinônimo de disciplina, normatização de condutas, disseminação de bons valores para convivência e tentativa de combate à violência.

Entrecruzadas por narrativas religiosas, as escolas constituem práticas de gênero e sexualidades ao compartilharem entendimentos naturalizados de heterossexualidade. Ao não problematizar ou discutir essas questões, favorecem um ambiente fértil para discursos homofóbicos. Em outro encontro com as/os estudantes pedimos 
que Junior comentasse uma de suas fotos da fachada da igreja Universal. Relembrando a conversa do dia anterior ele afirmou que frequenta os cultos com sua família e aprendeu que o primeiro relacionamento de amor começou com Adão e Eva. O menino disse que adora ir pra igreja e que "nós existimos por causa do amor deles [Adão e Eva] e de Deus por nós. Por isso não pode ter gays.” A história de Adão e Eva foi narrada por esse menino em outros momentos. Junior relatou episódios de um programa televiso evangélico e disse: "eu quero seguir o trono de Deus lá na fonte".

Nesse mesmo encontro, Pedro relatou que aprende tudo sobre Deus no culto: "a gente conversa, reza, canta. É importante saber as coisas de Deus". Diogo concordou e relatou outras atividades que realizava na igreja. Lucas afirmou que gosta de ir à igreja porque todo mundo o conhece e tem a oportunidade de aprender a tocar bateria. Ele ainda relatou que frequenta a escolinha da igreja para "aprender a orar, não brigar e não fazer negócio errado".

Vivências religiosas fazem parte da vida dessas crianças e estão presentes nas relações escolares. Não questionamos a doutrina pregada nas igrejas, mas, problematizamos como esses discursos entram nas salas de aula e, articulados a outros, se transformam em narrativas de preconceito e menosprezo aqueles que não atendem a sexualidade normatizada. Por exemplo, a criação de Adão e Eva foi inúmeras vezes citada pelos meninos como justificativa para a não aceitação da homossexualidade. Segundo eles, o homem e a mulher foram criados para gerar "frutos" (filhos), sendo esse o caminho "natural" para todos os animais.

Ao escutar que "Jesus não fez ele pra ser gay" e visualizar a concordância dos colegas, compreendemos que para esses meninos a heterossexualidade torna-se o caminho legítimo a ser seguido. Assim, a homofobia se instala e passa a funcionar como dispositivo que mantém concepções binárias entre sexo, gênero e sexualidade. Os meninos não demonstram dúvida de que a heterossexualidade é o comportamento correto e o justificam através de ensinamentos religiosos. Como consequência, combatem o que consideram errado.

Cremos que a desnaturalização de narrativas normativas, mesmo sendo assunto problemático, temido e omitido pelas/os educadoras/es, é uma atribuição da instituição escolar. Este tema concentra nossos interesses de pesquisa e representa desdobramentos possíveis como continuidade desta investigação por tratar-se de uma prática que se instalou e, gradativamente, se consolida nos ambientes escolares provocando interesse, dissensos e conflitos pessoais.

\section{Finalizando, provisoriamente}

As dimensões alcançadas pelos estudos da cultura visual atingem nossos interesses enquanto professores, pois nos importa explorar lugares de ruptura e promover projetos educativos apaixonantes que promovam protagonismo na produção e expansão das imagens. "Por isso, não nos enganamos e sabemos que não vemos o que queremos ver, mas sim aquilo que querem que vejamos. Disso advém a importância de questionar, na escola, as políticas de efeito dos olhares"(HERNANDEZ, 2013, p. 90). 
Interessa pensar como acontece esse jogo de produção da cultura visual e em quais meios estão engendrados para, a partir disso, projetar uma dimensão de protagonismo. As experiências culturais de Steve e seus colegas são privilegiadas pelas práticas educativas? Estas crianças tem oportunidade de refletir criticamente seu entorno e as imagens com as quais convivem? Em que momento são protagonistas na produção de imagens? Que outros olhares podemos deter a partir da relação de Steve com seu personagem preferido Ben 10 e seus colegas em sala de aula?

Esse é um dos pressupostos da educação da cultura visual, não entendida apenas como proposta pedagógica, mas, como ação, projeto reflexivo e processo investigativo que procura compreender como a relação dos sujeitos com determinadas imagens e artefatos consolidam interpretações e maneiras de ver ao longo da história. De acordo com Nascimento, (2011, p. 213), é "possível presumir que o interesse principal [da cultura visual] é tentar confrontar diferentes modos de ver, dizer, pensar e fazer veiculados pelas imagens".

Duvidar de interpretações naturalizadas, romper com narrativas estáveis, questionar crenças consolidadas, desconfiar de verdades preestabelecidas que, muitas vezes, nem nos damos conta, e criar possibilidades para outras e diferentes maneiras de entender a cultura das imagens são objetivos do campo reflexivo/político da cultura visual. No processo de análise e reflexão da interação dos sujeitos com imagens e artefatos culturais não interessa se há verdades a serem identificadas ou "mensagens ocultas" a serem desveladas, pois o que se considera está em como normatizamos padrões de pensamento sem deixar possibilidades para o ato de duvidar.

\section{Referências}

ANDRÉ, M. A pesquisa no cotidiano escolar. In: FAZENDA, I. C. A. (Org.). Metodologia da Pesquisa Educacional. São Paulo: Cortez, 1991, p. 35-45.

ASKEW, S.; ROSS, C. Los chicos no lloran: el sexismo en educación. Barcelona: Paidós Educador, 1991.

CLIFFORD,J. Introducción: verdades parciales. In: CLIFFORD, J.; GEORGE, M. E. (Orgs.). Retóricas de la antropologia, Madri: Júcar, 1991, p. 25-60.

CONNELL, R. W. La organización social de la masculinidad, In: LOMAS, C. (Org.) ¿Todos los hombres son iguales? Identidades masculinas y cambios sociales. Barcelona: Paidós, 2003, p. 31-54.

ECKERT, C.; ROCHA, A. L. C. Etnografia: saberes e Práticas. Revista Iluminuras - Publicação eletrônica do Banco de Imagens e Efeitos Visuais, v. 9, n. 21, 2008.

GARCIA, F. H. Hombre... Hombre... Hombre... Un estudio singular en torno a las representaciones de la masculinidad en el contexto educativo espanol de la década de los setenta. In: MARTINS, R.; MARTINS, A. F. (Orgs.). Interações com visualidades em contextos de ensinar e aprender. Coleção Desenredos - Programa de Pós-Graduação em Arte e Cultura Visual, Goiânia UFG, 2012, p. 125-150.

HERNANDEZ, F. Pesquisar com imagens, pesquisar sobre imagens: revelar aquilo que permanece invisível nas pedagogias da cultura visual. In: MARTINS, R.; TOURINHO, I. (Orgs.). Processo e Práticas de Pesquisa em Cultura Visual e Educação. Santa Maria, Editora UFSM, 2013, p. 77-95. 
MEYER, D. E.; SOARES, R. F. Modos de ver e de se movimentar pelos "caminhos" da pesquisa pós-estruturalista em educação: o que podemos aprender com - e a partir de - um filme. In: COSTA, M. V.; BUJES, M. I. E. Caminhos investigativos III: riscos e possibilidades de pesquisar nas fronteiras. Rio de Janeiro: DP\&A, 2005, p. 23-44.

NASCIMENTO, E. A. Singularidades da educação da cultura visual nos deslocamentos das imagens e das interpretações. In: MARTINS, R.; TOURINHO, I. (Orgs). Educação da cultura visual: conceitos e contextos. Santa Maria: Editora UFSM, 2011, p. 209-226.

TOURINHO, I.; MARTINS, R. Imagens como conhecimento e investigação. In: MARTINS, R.; TOURINHO, I. (Orgs.). Processo e Práticas de Pesquisa em Cultura Visual e Educação. Santa Maria, Editora UFSM, 2013, p. 13-17.

. Reflexividade e pesquisa empírica nos infiltráveis caminhos da cultura visual. In: MARTINS, R.; TOURINHO, I. (Orgs). Processos e Práticas de Pesquisa em Cultura Visual e Educação. Santa Maria: Editora UFSM, 2013, p. 61-76.

Nota

* Professora doutora da Universidade Federal de Pernambuco, Recife, Pernambuco, Brasil.

\section{Correspondência}

Luciana Borre Nunes - Universidade Federal de Pernambuco, Centro de Artes e Comunicação. Cidade Universitária, CEP: 50670-901 - Recife, Pernambuco - Brasil.

E-mail: lucianaborre@yahoo.com.br

Recebido em 21 de setembro de 2015

Aprovado em 11 de abril de 2016 